\title{
Postactivation potentiation improves jumps performance in children ages 6 to 8 years old
}

\author{
Camila Gerber ${ }^{1}$, Paolo Sirieiro', Igor Nasser ${ }^{1}$, Christopher Taber², Humberto Miranda' \\ 'School of Physical Education and Sports, Federal University of Rio de Janeiro, Brazil. 2Department of Physical Therapy and Human Movement Science, Sacred Heart University, \\ Fairfield, Connecticut, USA.
}

doi: 10.18176/archmeddeporte.00043

Recibido: $22 / 05 / 2020$

Aceptado: 08/03/2021

Post-activation Potentiation. Youth. Jumps. Neuromuscular.

\section{Summary}

Introduction: The aim of the present study was to investigate the effects of postactivation potentiation (PAP) in vertical and horizontal jump performance in pre-pubertal children.

Material and method: One hundred and nineteen children ( 65 girls and 54 boys; $6.8 \pm 0.7$ years old; $124.5 \pm 6.4 \mathrm{~cm} ; 25.2 \pm$ $5.1 \mathrm{~kg}$ ) participated in this study. This was a transversal cross-sectional study which incorporated a within-subjects repeatedmeasures design, where participants completed all protocols. The experimental procedure required four total testing, separated by one week, using a counterbalanced. This study investigated jumping performance associated with weighted jumps, lowload vertical jumps, and horizontal jumps. During two sessions the participants performed vertical jumps with and without PAP, the other two sessions the same procedures were performed for horizontal jumps. The PAP protocol consisted of one set of five weighted countermovement jumps with low-load (10\% of body mass) and a rest interval of four minutes prior to the jump tests. Paired t-tests were used between conditions (PAP and control) in the vertical jump and horizontal jump test. In addition, Cohen's d effect size and 95\% confidence interval was used.

Results: Significant jump height was observed in the vertical jump in the PAP condition compared to the control condition $(p=0.007)$. Similar results were observed for the horizontal jump tests, with significant longer distance observed in the PAP condition $(p=0.036)$.

Conclusions: Pre-pubertal children can benefit from the effects of PAP in vertical and horizontal jumping performance when preceded by low-load ballistic movements. A protocol implementing low-loads, determined by a relative percentage of body mass is effective to promote PAP for young children.

\section{La potenciación postactivación mejora el rendimiento de saltos en niños de 6 a 8 años}

\section{Resumen}

Introducción: El objetivo del presente artículo fue investigar los efectos de la potenciación postactivación (PAP) en el rendimiento del salto vertical y horizontal en niños prepuberal.

Material y método: Ciento diecinueve niños (65 niñas y 54 niños; $6,8 \pm 0,7$ años; $124,5 \pm 6,4 \mathrm{~cm} ; 25,2 \pm 5,1 \mathrm{~kg}$ ) participaron en este artículo. Este fue un estudio transversal que incorporó un diseño de medidas repetidas dentro de los sujetos, donde los participantes completaron todos los protocolos. El procedimiento experimental requirió cuatro pruebas totales, separadas por una semana, utilizando orden aleatorio. Este estudio analizó el rendimiento de salto asociado con saltos ponderados, saltos verticales de baja carga y saltos horizontales. Durante dos sesiones, los participantes realizaron saltos verticales con y sin PAP, en las otras dos sesiones se realizaron los mismos procedimientos para saltos horizontales. El protocolo PAP consistió en un conjunto de cinco saltos de contra movimiento ponderados con baja carga (10\% de la masa corporal) y un intervalo de descanso de cuatro minutos antes de las pruebas de salto. Se utilizaron pruebas t pareadas entre condiciones (PAP y control) en la prueba de salto vertical y salto horizontal. Además, se utilizó el tamaño del efecto de Cohen y el intervalo de confianza del $95 \%$. Resultados: Se observó una altura de salto significativa en el salto vertical en la condición PAP en comparación con la condición de control $(p=0,007)$. Se observaron resultados similares para las pruebas de salto horizontal, con una distancia significativamente mayor observada en la condición PAP $(p=0,036)$.

Palabras clave: Conclusiones: Los niños prepuberales pueden beneficiarse de los efectos de la PAP en el rendimiento de salto vertical y horizontal cuando están precedidos por movimientos balísticos de baja carga. Un protocolo que implementa cargas bajas, determinado por un porcentaje relativo de la masa corporal, es efectivo para promover la PAP en niños pequeños. 


\section{Introduction}

Postactivation potentiation (PAP) is an acute phenomenon of enhanced force output and power development following a maximal or near maximal muscle contraction'. One factor that contributes to the effects of PAP is attributed to neural activation in which the prior muscle contraction stimulus increases the capacity to recruitment higher threshold motor units during subsequent activity ${ }^{2,3}$. Another factor is attributed to skeletal muscle alterations, regulated by the release of $\mathrm{Ca}^{2+}$ molecules during contraction and phosphorylation of myosin regulatory light chains, which alter the myosin structure and increase the rate of cross bridge cycling 4 . Additionally, alterations in muscle architecture may occur, with a decrease in pennation angle and enhancements in force transmission to the tendon, which may increase the effects of PAP, although these mechanisms have yet to be fully elucidated ${ }^{2,5}$.

PAP has been studied extensively with various protocols, exercises implemented and different populations but less is known about these effects in children'. Previous studies with youth subjects reported that both pre-pubertal and post-pubertal subjects can benefit from the effects PAP on performance ${ }^{6,7}$. Paasuke et al. ${ }^{7}$ showed that although post-pubertal boys (16-years-old) showed higher maximal voluntary contraction (MVC) than pre-pubertal boys (11-years-old), both improved plantar flexor muscle twitch peak force during a PAP complex. However, PAP protocols generally use heavy loads, $\geq 80 \%$ of ${ }^{1}$ repetition maximum (RM), but when prescribing resistance exercise for children, it is not recommended to use heavy loading with this population ${ }^{1,8}$.

Strategies to promote PAP in very young children are scarce and published meta-analyses have no specific suggestions to improve PAP effects for this population ${ }^{1,8}$. Investigating PAP in young children can contribute to understanding the physiological mechanisms and which populations can successfully implement this type of training. Additionally, resistance training to improve strength and power is an increasingly popular training modality with children since several guidelines have been published over the years citing its efficacy ${ }^{9-11}$ and additional methods to optimize prescription is necessary for strength and conditioning. The addition of a stimulus of conditioning activity (CA) and subsequent power activity can contribute to neural development and basic motor skills for children. Therefore, based on this previous information, the purpose of this study was to investigate the effects of a PAP protocol on vertical and horizontal jumps in pre-pubertal children.

\section{Material and method}

\section{Experimental approach to the problem}

This was a transversal cross-sectional study which incorporated a within-subjects repeated-measures design, where participants completed all protocols in random order. The experimental procedure required a total of four visits, each separated by one week. All subjects performed the visits during afternoon, at the same time, between midday to 4:00 pm. During two visits, participants performed a vertical jump test and a horizontal jump test. The other two visits the same tests were used, however, a PAP protocol was performed before them. Before each protocol, a dynamic warm-up was used, consisting of one minute of slow running, 30 seconds high knees, 30 seconds raising heels, 30 seconds with low jumps, and 30 seconds of jumping jacks. Two minutes of passive rest was provided before PAP protocol or jump tests. At the day without PAP, children performed jump tests following the same warm-up procedure and rest interval. Detail of the methods is displayed in Figure 1.

\section{Subjects}

One hundred and nineteen children (65 girls and 54 boys) aged between 6 to 8 years old participated in this study. Sample characteristics can be found in Table 1. A priori sample size was estimated by the software G*Power (version 3.1.9.2. Dusseldorf, DEU) previously recommended by Beck ${ }^{12}$. Considering an effect size of 0.5 , an a error of 0.01 and the power ( 1 - $\beta$ ) of 0.99 , the total sample calculation was 100 subjects. A larger sample was recruited to account for subject dropout which could

Figure 1. Study design and experimental protocols.
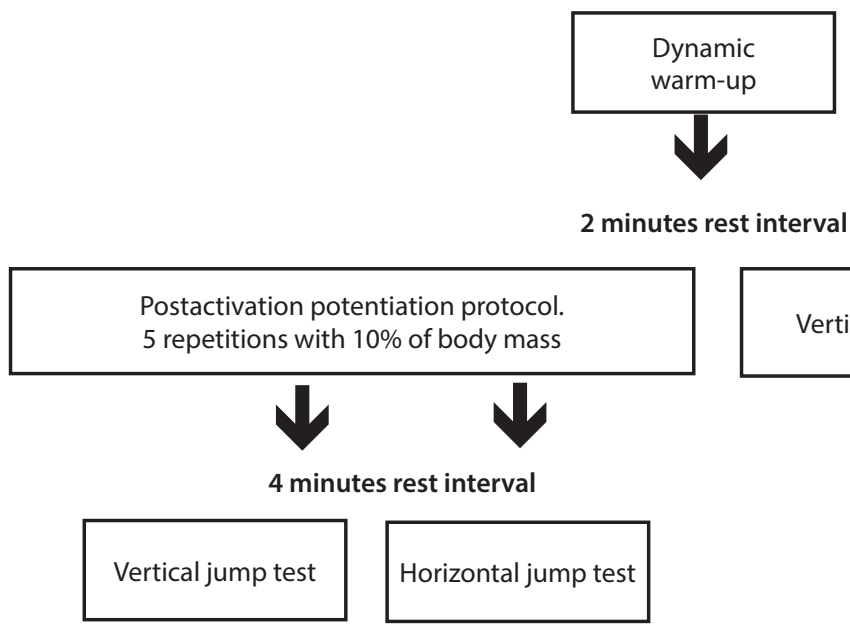

Vertical jump test control

Horizontal jump test control 
Table 1. Sample characterization (mean and standard deviation).

\begin{tabular}{lccc}
\hline & $\begin{array}{c}\text { Group } \\
(\mathbf{n}=\mathbf{1 1 9})\end{array}$ & $\begin{array}{c}\text { Girls } \\
(\mathbf{n}=\mathbf{6 5})\end{array}$ & $\begin{array}{c}\text { Boys } \\
(\mathbf{n}=\mathbf{5 4})\end{array}$ \\
\hline Age (years) & $6.8 \pm 0.7$ & $6.8 \pm 0.7$ & $6.9 \pm 0.7$ \\
Height (cm) & $124.5 \pm 6.4$ & $124.4 \pm 6.3$ & $125.3 \pm 6.5$ \\
Weight (kg) & $25.2 \pm 5.1$ & $24.4 \pm 4.6$ & $26.2 \pm 5.7$ \\
BMl & $16.17 \pm 2.34$ & $15.76 \pm 2.48$ & $16.66 \pm 3.46$ \\
\hline
\end{tabular}

BMI: body mass index.

confound the results. Participants were healthy and not engaged in any kind of high-performance sports or strength and conditioning training. All subjects were considered in the infancy phase, without complete maturation $^{10}$. On the first visit to the laboratory, participants had height and body mass measured using a measuring tape attached on the wall and a digital scale (Worker, São Paulo, Brazil) and were familiarized with the jump tests. Body mass were measured in kilograms and height were determined with $0.5 \mathrm{~cm}$ intervals. In the familiarization session, subjects were instructed of the procedures of the jump tests, position of the arms and the exercise that was used. During experimental sessions, the researchers observed carefully all procedures. Subjects were excluded for any injuries on knee, ankle and foot the that would compromise the jumping exercise execution and/or jump tests. This study followed the ethical procedures for experimental research with humans, according to the resolution 466/2012 of National Health Council and was approved by the ethics committee in research at University under the number: 68385017.8.0000.5257. An informed parental consent which all procedures adopted in this study were read and signed by parents prior to the participation of the children in this study.

\section{Postactivation potentiation protocol}

On the day of vertical jump test, vertical countermovement jumps were used. On the day of horizontal jump test, horizontal countermovement jumps were performed. Two minutes after the dynamic warm-up, participants performed a PAP protocol, previously reported by Burkett et al. ${ }^{13}$ that compared four warm-up protocols consisting of: weighted jumps with $10 \%$ of body mass; submaximal jump warm-up with $75 \%$ of the participants'maximum vertical jump; stretching protocol with 14 position; and a no warm-up control protocol. Significantly higher vertical jump performance was observed in the protocol of five repetitions with $10 \%$ of body mass. Based on it, the PAP protocol consisted of one set of five jumps with the load corresponding to $10 \%$ of body mass. However, in the study of Burkett et al. ${ }^{13}$, young adults jumped over a box with the height of 63.5 centimeters. In this study, participants performed free jumps on the floor, with instructions to jump as high as possible, since these children were not able to jump over the previously mentioned box height. During the PAP jumps, subjects held weight plates in their hands and the values were rounded when necessary. Four minutes of passive was provided between the PAP protocol and jump tests. Generally, greater rest interval is used between CA and jump test, however, this recommendation is made for high-load protocols?

\section{Jump tests}

In the vertical jump test, initial measurement of standing reach height was obtained. Then, the participants were positioned near the tape measure and instructed to jump as high as possible and touch the tape measure with the fingertips which were marked with chalk. During all testing, strong verbal encouragement was provided for each subject. Subjects were allowed to use arm swing and self-selected depth in the countermovement jump. Three maximal attempts were provided and the best of these jumps was used for analysis. Jump height was determined as the distance between the outstretched standing reach and the mark made at the apex of the vertical jump.

For the horizontal jump test, the participants were positioned on the 0 -cm marked point, with feet shoulder width apart. During test, the subjects were instructed to jump as far as possible. Verbal encouragement was provided during each jump and subjects were allowed to arm swing and self-selected countermovement depth. Three maximal attempts were given and the best of theses jumps was used for analysis. Jump distance was determined as the distance from the starting line to the back of the heel upon landing marked with a tape measure ${ }^{14}$. During landing, subjects should not move the foot due to unbalance. When this happened, an additional attempt was made.

\section{Statistical analyses}

The statistical analyses were initially performed using the ShapiroWilk normality test and homoscedasticity test (Bartlett's criterion). Descriptive and parametric statistics were used for all analyses, with the results presented as means and standard deviations. Paired t-tests were used between conditions (PAP and control) in the vertical jump and horizontal jump test. Statistical analyses were performed using the software SPSS (version 20, Chicago, IL, USA), using $p \leq 0.05$ as a standard of statistical significance. In addition, Cohen's d effect size (ES) and 95\% confidence interval (CI) was used, consisted of the difference between two means divided by pooled standard deviation, and rated according to the magnitude of $<0.20$ trivial; 0.20-0.49 small; 0.50-0.79 moderate; and $>0.80$ large $^{15}$.

\section{Results}

Significant differences were observed between conditions for both tests $(p<0.05)$. The PAP improved the vertical jump test when compared to control (Figure 2; $22.29 \pm 5.13$ vs. $21.57 \pm 4.68 \mathrm{~cm}$, respectively; $p=$ 0.007). Cohen's d revealed a trivial magnitude of the difference of 0.15 ( $95 \% \mathrm{Cl}=0.13-0.16)$. Similar results were observed for the horizontal jump test, with significantly longer distances in the PAP protocol when compared to control (Figure 3; $107.05 \pm 17.35$ vs. $104.97 \pm 18.76 \mathrm{~cm}$, respectively; $p=$ 0.036). Cohen's d revealed a trivial magnitude of the difference of 0.11 ( $95 \%$ $\mathrm{Cl}=0.10-0.13)$.

\section{Discussion}

The present study revealed that children ages 6 to 8 years old can improve performance of vertical and horizontal jumps following a PAP 
Figure 2. Vertical jump test comparing the postactivation potentiation (PAP) protocol and control condition.

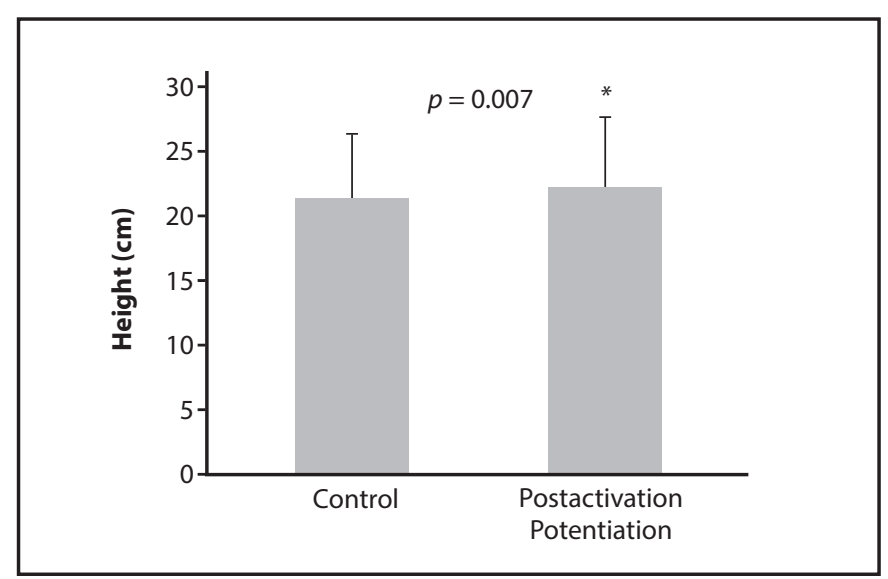

*Significant higher jump height for PAP.

Figure 3. Horizontal jump test comparing the postactivation potentiation (PAP) protocol and control condition.

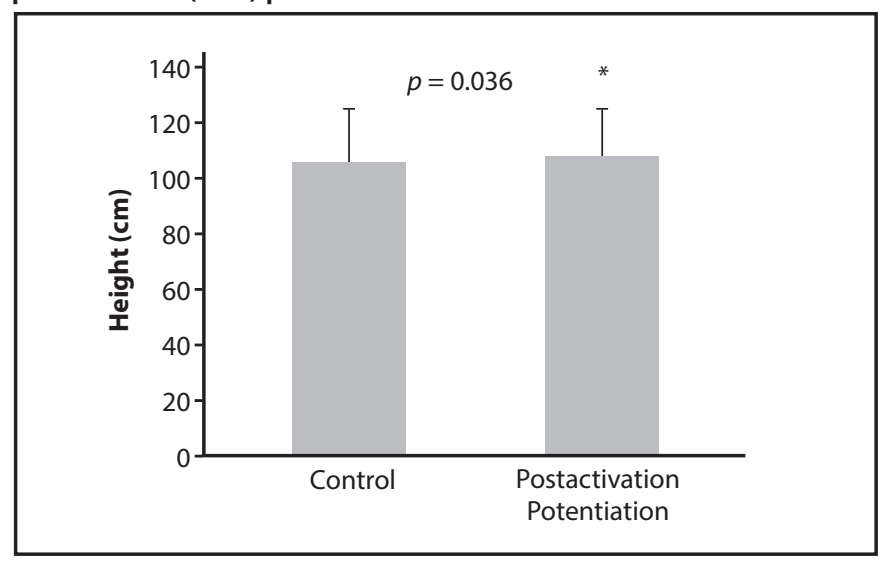

*Significant greater jump distance for PAP.

protocol. However, this improvement is clinically relevant, based on a trivial magnitude of this difference. Pre-pubertal children generally have lower twitch force production when compared to post-pubertal and young adults ${ }^{7}$. An incomplete maturation process, with lower muscle activation and reduced intra- and intermuscular coordination may compromise the force production and motors skills in young children 9 . Seitz et al. ${ }^{16}$ found a large correlation between PAP responses during an isokinetic protocol related to maximal knee extensor torque $(r=0.62)$, quadriceps cross sectional area $(r=0.68)$ and muscle volume $(r=0.63)$. This finding suggests that training status, with greater strength and muscle volume, will influence the PAP response. The participants of the present study were very young, without previous experience in resistance training to improve power and strength and still achieved a positive PAP effect with low-load jumping movements.

The findings of this study are different from Arabatzi et al. ${ }^{6}$ that did not observe PAP benefit for both pre-pubertal boys when during squat jump (SJ) test. This is probably attributed to CA applied in the children previous SJ, which consisted of an isometric stimulus. The present study used a protocol based on an earlier study ${ }^{13}$ that showed higher vertical jump performance following the protocol of five repetitions with 10\% of body mass in the collegiate football players, suggesting a specific lowload warm-up before jump training may be beneficial. These findings suggest that the CA should simulate the movement specificity that will be performed in the main activity. Another important consideration is that not only higher loads should be used in a PAP protocols, but further studies should consider low-load protocols combined with explosive movements, especially for those who are untrained and pre-pubertal.

Considering the rest interval between the PAP protocol and the jump testing, this study corroborates with the previous meta-analyses of Dobbs et al. ${ }^{17}$ which concluded that three to seven minutes are appropriate to recover from acute fatigue generated during the preceding movement and the main activity. This study used a four minutes passive rest interval, although the recommendation for longer rest intervals generally are made for higher loads PAP protocols ${ }^{18}$. The rest interval is an important consideration since an optimal time between conditioning activity and main activity should be used to overcome the acute fatigue while still maintaining the potentiation effect, thus, improving performance ${ }^{18}$. Previous studies indicate that a short-rest interval can be detrimental to performance due to excessive fatigue, and longerrest periods may dissipate the potentiation effect ${ }^{19,20}$. However, these recommendations are generally made when high-load PAP protocols are used in adults, differing from this study. Hatzikotoulas et al. ${ }^{21}$ showed that pre-pubertal boys are more fatigue resistant than men after a protocol performed to exhaustion. This suggest that the rest interval between CA and main activity for children may be shorter than adults, especially when low-loads are used during the CA.

The major limitation in this study was the inclusion of untrained subjects without previous experience in resistance training. However, due to the age of the children, it is difficult to recruit trained young athletes. Additionally, this study provides evidence of the effects of PAP in young children, independent of training status. It is important to highlight that the development of the maturation process is more important than sports performance for very young children recruited in this study. However, this study brings novel for literature of PAP that can be used and even prior a RT session as warm-up or in physical education classes for motor development. Future studies should consider investigating potential mechanisms of PAP in very young children, which may differ from adolescents and adults.

In conclusion, this study demonstrated that PAP can improve vertical and horizontal jumps performance in very young children, between the ages of 6 to 8 years old. As practical application of the results of this study, strength and conditioning coaches should consider incorporating this specific low-load training strategy as warm-up to acutely improve power in youth athletes. A protocol implementing low-loads, determined by a relative percentage of body mass is effective to promote PAP for young children, thus being an efficient and safe strategy.

\section{Conflict of interest}

The authors do not declare a conflict of interest. 


\section{Bibliography}

1. Seitz $L B$, Haff GG. Factors modulating post-activation potentiation of jump, sprint, throw, and upper body ballistic performances: a systematic review with meta-analysis. Sports Med. 2015;46:231-40.

2. Tillin NA, Bishop D. Factors modulating post-activation and its effect on performance of subsequent explosive activities. Sports Med. 2009;39:147-166.

3. Xenofondos A, Dimitrios P, Christos K. On the mechanisms of postactivation potentiation: the contribution of neural factors. Journal of Physical Education and Sports. 2014;14:134-7.

4. Maclntosh BR. Role of calcium sensitivity modulation in skeletal muscle performance. News Physio/ Sci. 2003;18:222-25.

5. Reardon D, Hoffman JR, Mangine GT, Wells AJ, Gonzalez AM, Jajtner AR, et al. Do changes in muscle architecture affect post-activation potentiation? J Sports Sci Med. 2014;13:483-92.

6. Arabatzi F, Patikas D, Zafeiridis A, Giavroudis K, Kannas T, Gourgoulis V, et al. The postactivation potentiation effect on squat jump performance: age and sex effect. Pediatr Exerc Sci. 2014;26:187-94.

7. Paasuke M, Ereline J, Gapeyeva $H$. Twitch contraction properties of plantar flexors muscles in pre- and post-pubertal boys and men. Eur J Appl Physiol. 2000;82:459-64.

8. Wilson JM, Duncan NM, Marin PJ, Brown LE, Loenneke JP, Wilson SMC, et al. Meta-analysis of postactivation potentiation and power: effects of conditioning activity, volume, gender, rest periods, and training status. J of Strength and Cond Res. 2013;27:854-9.

9. Lloyd RS, Faigenbaum AD, Stone MH, Oliver JL, Jeffreys I, Moody JA, et al. Position statement on youth resistance training: the 2014 international consensus. Br J Sports Med. 2014;48:498-05.

10. Myers AM, Beam NW, Fakhoury JD. Resistance training for children and adolescents. Transl Pediatr. 2017;6:137-43.
11. BeckTW.The importance of a priori sample size estimation in strength and conditioning research. J of Strength and Cond Res. 2013;27:2323-37.

12. Burkett LN, Wayne PT, Ziuraitis J. The best warm-up for the vertical jump in college-age athletic men. J of Strength and Cond Res. 2005;19:673-9.

13. Seitz LB, Mina MA, HaffGG. Postactivation potentiation of horizontal jump performance across multiple sets of a contrast protocol. J of Strength and Cond Res. 2016a;30:2733-40.

14. Hopkins WG, Marshall SW, Batterham AM, Hanin J. Progressive statistics for studies in sports medicine and exercise science. Med Sci Sports Exerc. 2009;41:3-13.

15. Faigenbaum AD, Lloyd RS, Myer GD. Youth resistance training: past practices, news perspectives, and future directions. Pediatr Exerc Sci. 2013;25:592-04.

16. Seitz LB, Trajano GS, Haff GG, Dumke GG, Tufano JJ, Blazevich AJ. Relationships between maximal strength, muscle size, and myosin heavy chain isoform composition and postactivation potentiation. Appl Physiol Nutr Metab. 2016b;41:491-7.

17. Dobbs WC, Tolusso DV, Fedewan MV, Esco MR. Effects of postactivation potentiation on explosive vertical jump: a systematic review and meta-analysis. J of Strength and Cond Res. 2018;33:2009-18.

18. Gouvêa AL, Fernandes IL, César EP, Silva WAB, Gomes PSC. The effects of rest intervals on jumping performance: a meta-analysis on post-activation potentiation studies. $J$ Sports Sci. 2012;31:459-67.

19. Crewther BT, Kilduff LP, Cook CJ, Middleton MK, Bunce PJ, Yang G. The acute potentiating effects of back squats on athlete performance. J of Strength and Con Res. 2011;25:331925.

20. Turner AP, Bellhouse S, Kilduff LP, Russel M. Postactivation potentiation of sprint acceleration performance using plyometric exercise. J of Strength and Cond Res. 2015;29:343-50.

21. Hatzikotoulas K, Patikas D, Ratel S, Bassa E, Kotzamanidis C. Central and peripheral fatigability in boys and men during maximal contraction. Med Sci Sports Exerc. 2014;46:1326-33. 